\title{
Taxa-Area Relationship (TAR) of Microbial Functional Genes with Long-Term Fertilization
}

Yuting Liang1, Liyou

ABSTRACTS

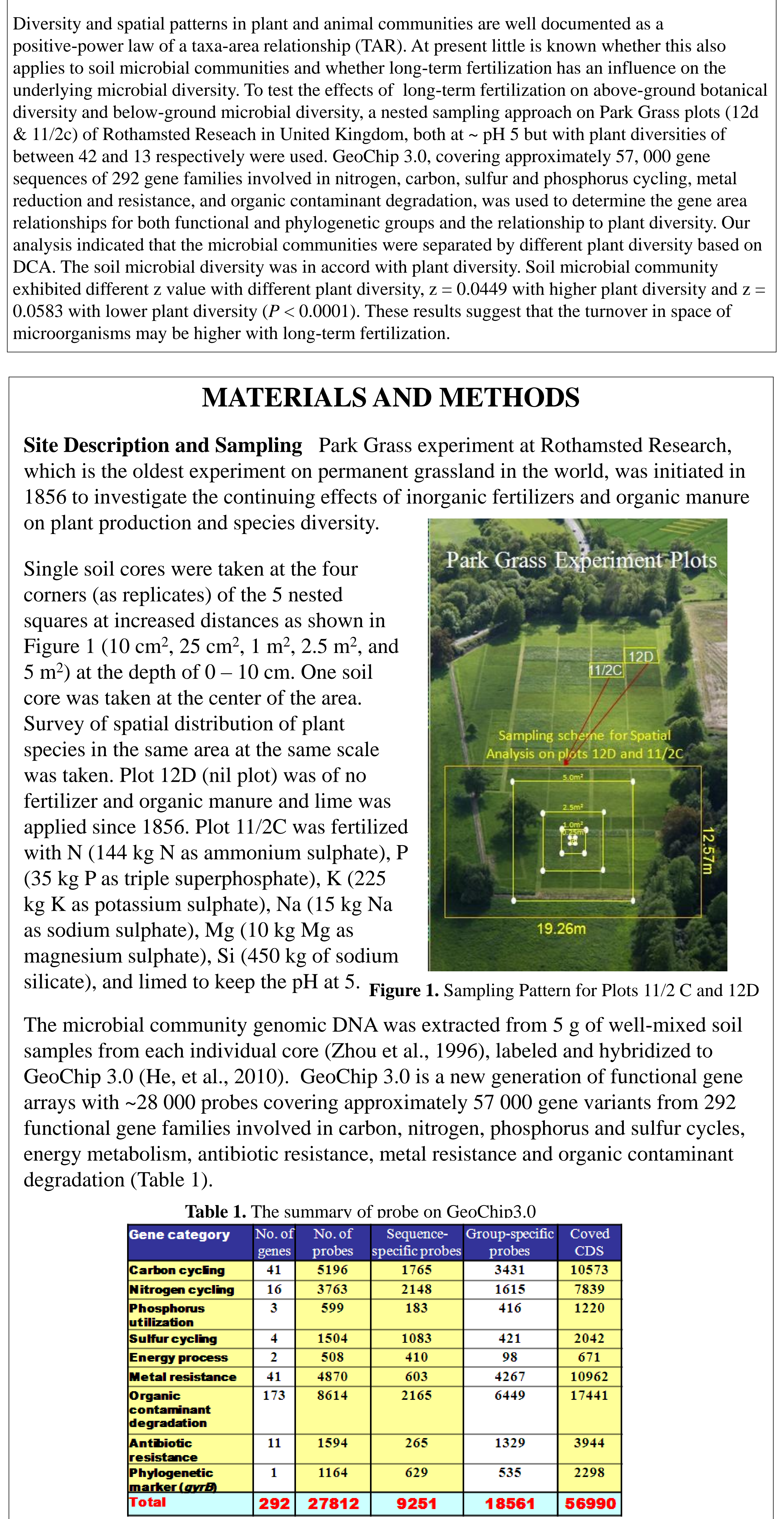

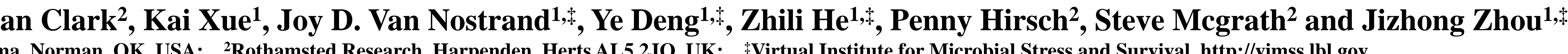

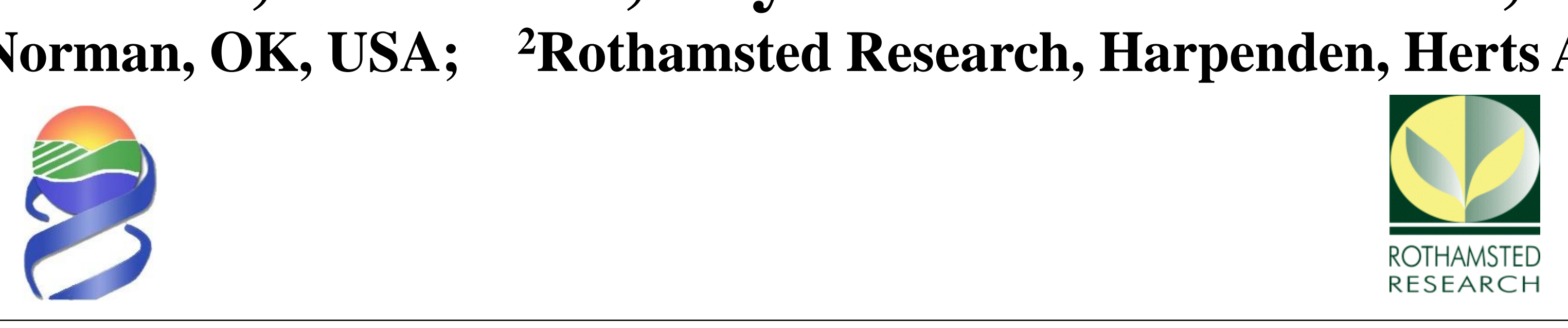

RESULTS AND DISCUSSIONS

$z$ value of microbial functional and phylogenetic groups.

- values were determined by fitting the linear regression equation $(\log S=\log c+z \log A)$, where $S$ is species richness and $A$ is area. The $z$ values for individual functional and phylogenetic groups were estimated based 0 the individual functional gene sequences $w$ within each group. $t$ and $P$ values are from one-sample $t$ tests on

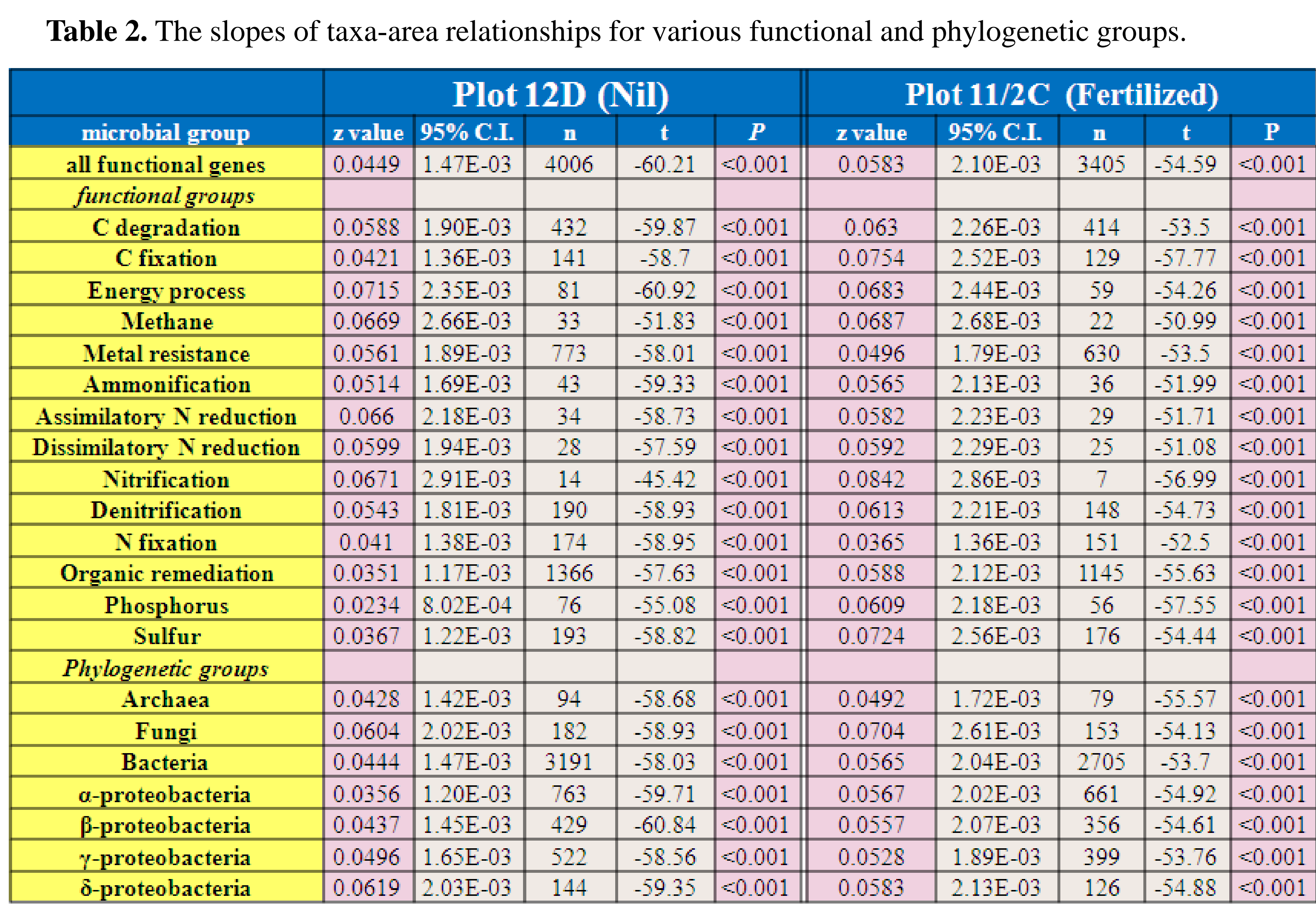

Significant TARs were observed for all functional and phylogentic groups of both fertilized site and control sile, for all functional genes, $z=0.0449$ in control site (12D) and $z=0.0583$ ( (11/2C) in fertilized site (Table $)$

Table 3.z value comparison between
fertilized and control sites.

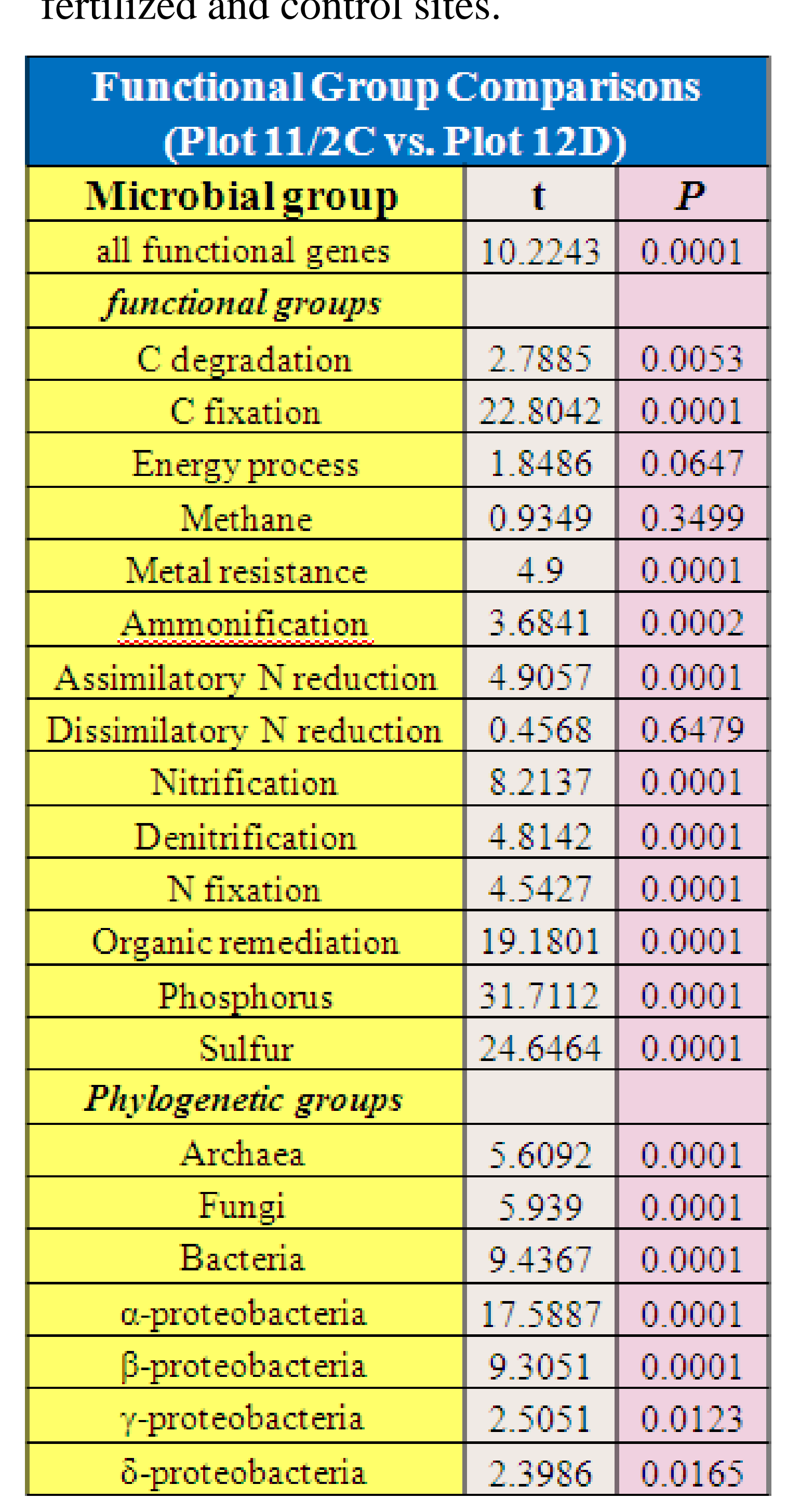

Considerable variations in the $z$ values were observed among dfferent functional and phylogenentic groups. The mean $z$ valuc $0.0483( \pm 0.009)$ for phylogenetic groups in non-fertilized site (12D). In comparison, the mean $z$ value was 0.0624 ( \pm 0.0115 ) for different functional gene groups and $0.0571( \pm 0.007)$ in tertilized sile $(1 / 2)$.

To determine whether the estimated $z$ values were significantly Afferen between fertilized site and non-fertilized site, test was (T)

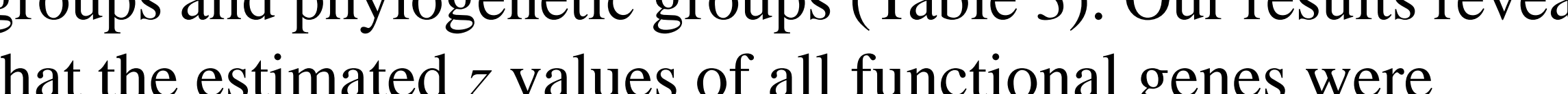
significantly different between $12 \mathrm{D}$ and $11 / 2 \mathrm{C}(P=0.0001)$. For different functional groups, $z$ values were significantly different or most nitrogen cycling processs, such as ammonification $(P=$ .0002), assimilatary yitrogen reduction $(P=0.0001)$

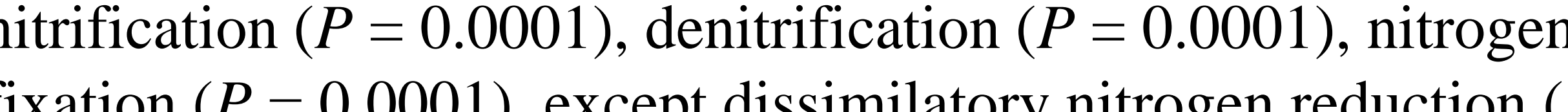
$=0.6479)$. In the mean time, it seems fertilization had a significant effects on $z$ values of other functional groups such as
carbon degradation $(P=0.0053)$. carbon fixation $(P=0.0001)$. carbon degradation $(P=0.0053)$, carbon fixation $(P=0.0001)$, metal resistance $(P=0.0001)$, phosphorus cycling $(P=0.0000)$,
sulfur cycling $(P=0.0001)$ and organic remediation $(P=0.0001)$

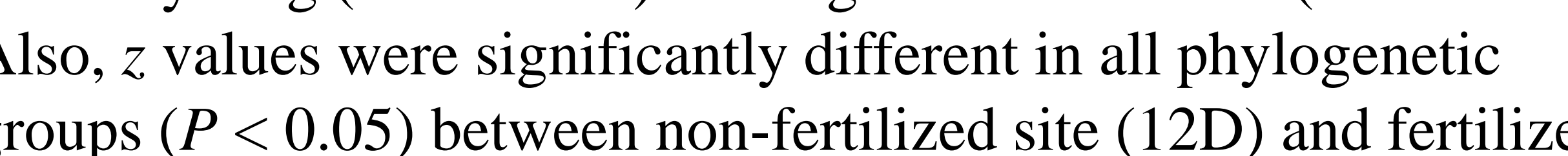
groups $(P<0.05)$ be
site $(11 / 2 C)$.

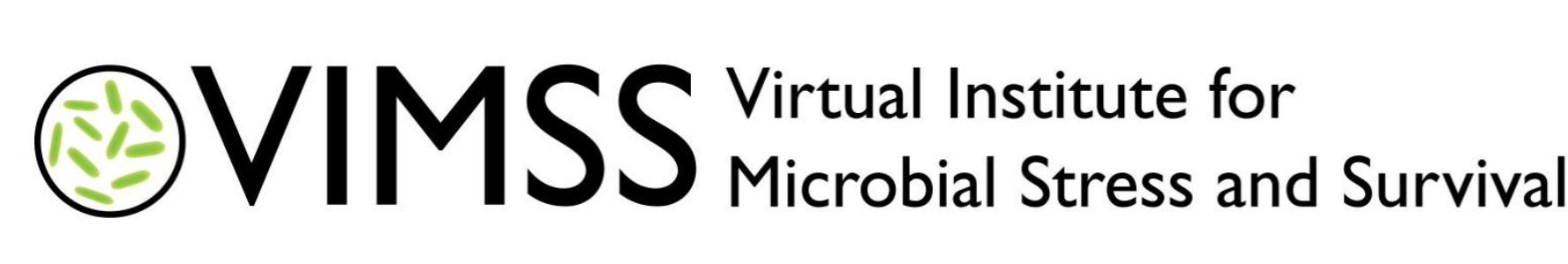

z value comparison of plants and microbial communities

in fertilized and control sites

Long-term fertilization significantly decreased the microbial functional diversity $(P=0.002)$, as well as

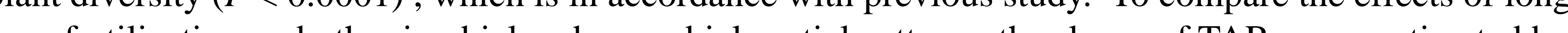
linear reges microbial functional genes and plant exhibited higher $z$ values with long-term fertilization.

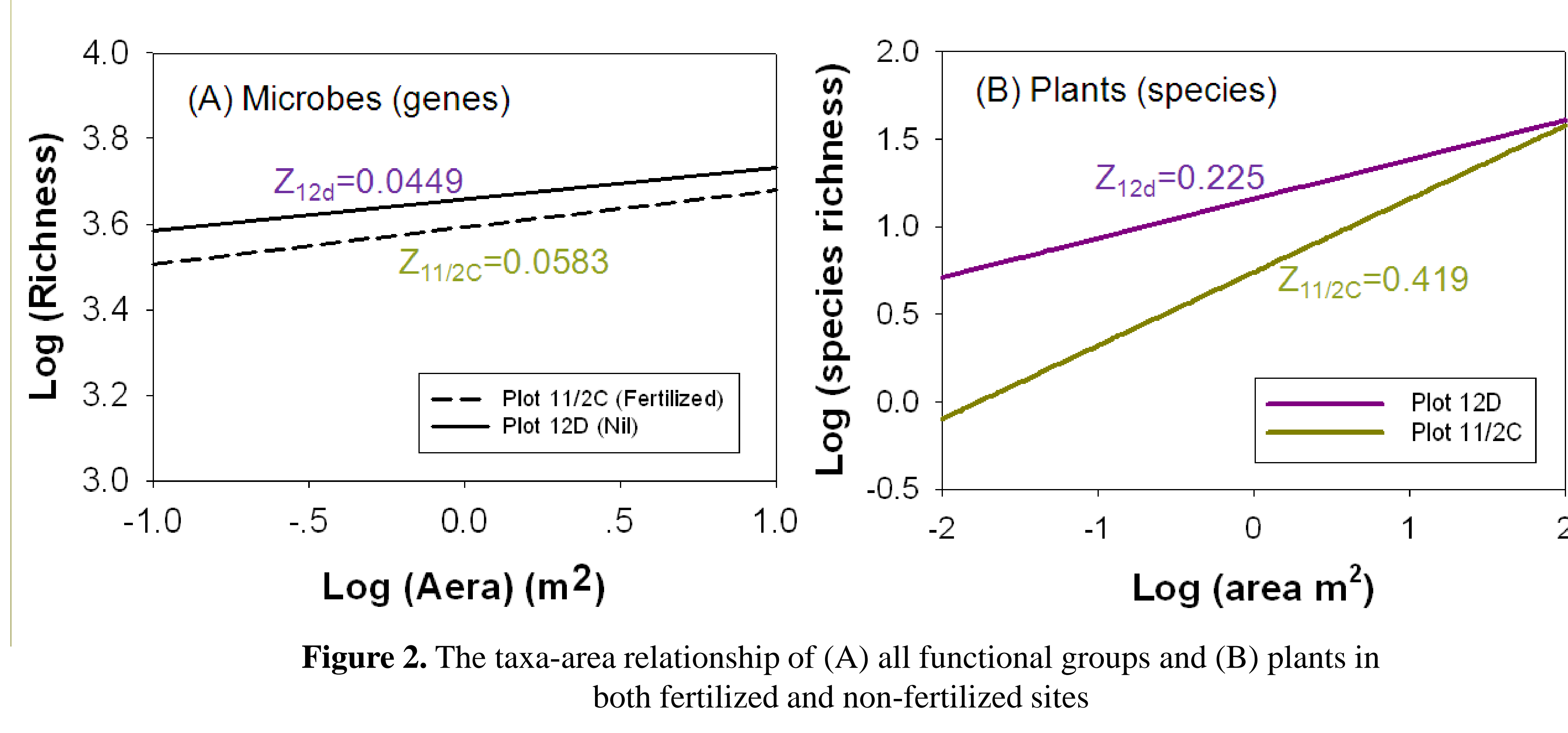

The $z$ value obtained in this study were compared with previously studies to obtain a general insights the spatial scaling of biodiversity across different organisms (Figure 3). The $z$ values for the plants $(0.0527 \pm 0.007)$ appears to be much lower than those of other organisms.

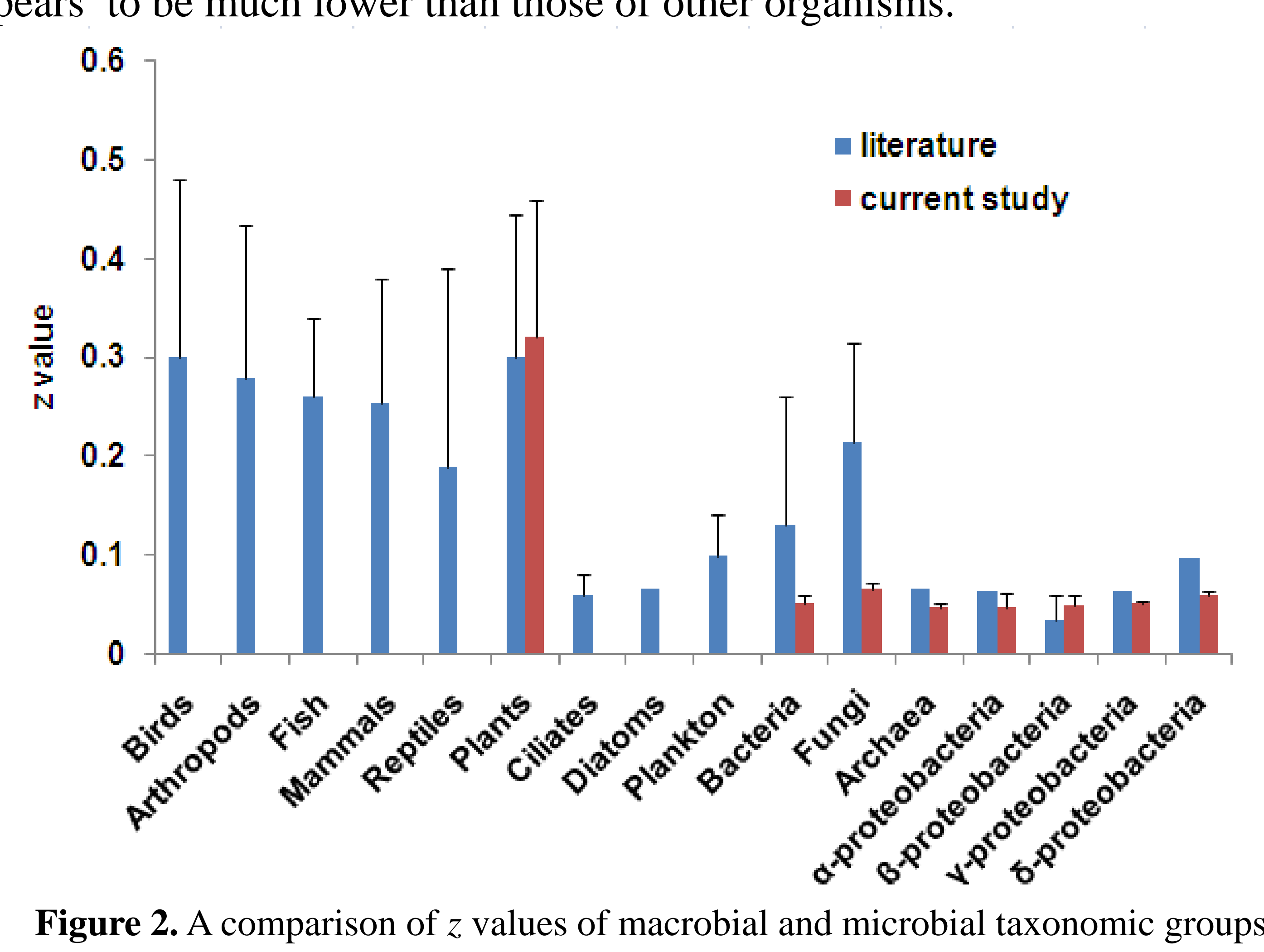

SUMMARY

Significant difference of microbial functional and phylogenetic spatial turnover was observed between lon term fertilized site and control site. $z$ values for both plane in space of microorganisms may be affected by human activities such as long-term fertilization.

ACKNOWLEDGEMENT 